\title{
USDA to study potential anti-social effects of sponsored research
}

FOLLOWING the US Department of Agriculture's decision to stop funding research that would throw farm workers out of their jobs (Nature 3 January 1980 page 5), Agriculture Secretary, Mr Bob Bergland, has now announced a study into the possible anti-social effects of all federally-funded research.

The task force that will undertake the study will concentrate on the $\$ 1$ million which the Department spends annually on research at universities and land grant colleges into the mechnisation of agricultural production. This has been subject to criticism that led to the decision to halt new funds for such research.

In a speech to the staff at the Department's Science and Education Administration at Reston, Virginia, $\mathrm{Mr}$ Bergland repeated that he would no longer support research whose benefits would be restricted to a particular locality or social

\section{New group to study cryptography policy}

WAYS of resolving conflicts between the academic freedom of researchers working on computer codes and the interests of national security are to be investigated by a group that has been established by the American Council of Education, under a grant of $\$ 32,000$ from the National Science Foundation.

The chairman of the study group will be Dr Werner Baum, dean of the college of arts and sciences at Florida State University. Dr Baum was previously chancellor of the University of Wisconsin at Milwaukee, where in 1978 a computer scientist, Dr George Davida, had a patent application for a new computer code blocked by the Department of Commerce following objections from the National Security Agency.

Dr Baum told Nature recently that he hoped the study group would be able to recommend policies and procedures which would both protect the legitimate academic and property concerns of universities and research institutions on the one hand, and the concerns of the US government about security on the other.

$\mathrm{He}$ added that this might involve changes in the law. In the Davida case, for example, which was successfully challenged by the university, Dr Baum pointed out that the NSA had no due process requirement covering demands that an individual should not publish the results of his research for national security reasons. Current law, he said, which goes back to group, or which posed a threat to the natural environment or social community.

"In the specific case of mechanisation research, this means that we will not put federal money into research where - all other factors being equal or neutral - the major effect of that research will be replacing an adequate and willing workforce with machines", Mr Bergland said.

However he added that the economic incentives of the market-place should be powerful enough to enable this type of research to be funded by private industry, either by itself or with the help of state funds.

Mr Bergland said that this policy was consistent with the department's responsibilities to meet national needs, rather than those of a particular group. The government should not finance research whose beneficiaries could, in an extreme case, use it "to gain control of the farm-to-

the post-war McCarthy period, may turn out to be non-constitutional.

The ACE working group was established after NSA director Admiral Bobby Inman last year suggested a dialogue with the scientific community on conflicts between academic freedom and security issues. The group will include representatives of professional societies such as the American Mathematical Society and the Computer Society of the Institute of Electrical and Electronic Engineers, as well as legal advisers. It is expected to produce a report within a year.

Last year Admiral Inman was quoted as supporting legislation which would control research and the subsequent publication of results of "a central core of critical cryptologic information ... that is likely to have a discernable adverse impact on national security."

\section{Battelle paints healthy picture of US R\&D}

IN contrast to the frequent complaints still heard about the health of US research and development, a surprisingly lively picture of the current situation is presented in the latest annual analysis by the Columbus Laboratories of the Battelle Memorial Institute. Taking R\&D expenditures across the board, Battelle estimates that these will grow by $19.7 \%$ in 1980 , to a total of $\$ 61.8$ billion. Within this total, industrial funding is expected to grow faster $(20.9 \%$ increase) than federal funding (19\% increase); but even given a predicted cost increase of $12 \%$, this still implies a $7 \%$ real market structure, monopolise the sources of finance at every step, and increase their profits by selling what may well be an inferior product at a price that is insulated from competition".

$\mathrm{He}$ pointed out that until recently, agricultural research had been evaluated almost exclusively in terms of what the research promised in the way of volume productivity gains; too often potentially significant negative economic and social effects were not factored into the evaluation.

" The result was a skewed cost-efficiency statistic and distorted perspective. If this is not remedied in the research evaluation process, it will surely handicap our ability to meet changing national priorities", $\mathrm{Mr}$ Berland said. This was the reason for establishing a task force to look for research projects involving "the dubious use of federal money."

growth in expenditure, reaching a new peak in total real funding of $R \& D$, the report says.

Despite the unfavourable economic climate, the Battelle report says that there are many intangibles, "particularly the reawakened feeling on the parts of many decision makers that $R \& D$ is essential to our long-term economic health - that favour greater-than-usual increase in support for research. The report says that its analysis indicates that the upward movement established over much of the past decade in R\&D expenditures is likely to continue, with the 1980 figures leading to an average increase over the past seven years of $3.3 \%$ in real terms. It estimates that during the decade of the 1980s real R\&D activity will increase at an average rate of approximately $3 \%$.

The major sector to indicate increases in both funding and performance of R\&D in 1980 is expected to be industry. In contrast, academic and other non-profit institutions are expected to register small decreases in the percentage of support and performance (3.5\% and $15.1 \%$ respectively); but there will still be significant increases in the total activity of each $(1.3 \%$ and $17.6 \%$ over the estimated 1979 figures).

The report says that therefore in spite of inflation and the desire of the Carter administration to balance the budget, there are signs of greater support for research. It points out in particular that industrial support is growing in fields affected by regulations and in those fields most directly influenced by the need for more energyefficient products and processes. 